\title{
Performance-based-plastic design method of reinforced concrete structure for operational performance level
}

\author{
Jati Sunaryati $^{1 *}$, Nidiasari Nidiasari ${ }^{1}$, and Rifqi Yuliandri $^{1}$ \\ ${ }^{1}$ Civil Engineering Department, Andalas University
}

\begin{abstract}
Under major load earthquakes, reinforced concrete structures designed according to the current codes will experience an inelastic deformation which is difficult to predict and control. Performance-based plastic design (PBPD) methodology is applied forward to design reinforced concrete structures in this study. In this method, as performance criteria, the target drift and yield mechanisms are preselected. Based on the work-energy balance principle, the design base shear is given as earthquake level and calculated as work required to push the structure as monotonically load to the target drift. The load equals the energy needed by an equivalent single degree of freedom in the same state. The plastic design is utilized to design the desired yield mechanism. The method was adopted on a 10-story reinforced concrete structure with an earthquake load in lateral forces based on SNI 1726:2019 and the Performance-Based Plastic Design (PBPD) method. Pushover analysis was carried out where the structure was pushed to obtain lateral load resistance followed by yielding gradually until plastic deformation occurred collapse From the pushover analysis, the ductility value for SNI 1726:2019 is less ductile than analytical using the Performance-Based Plastic Design (PBPD) method
\end{abstract}

\section{Introduction}

Important buildings such as schools, hospitals, office buildings, and even shopping centers in SNI 1726:2019 [1] are included in priority factor IV. By providing an earthquake value more significant than the planned earthquake, these important buildings are expected to have an operational performance level during a moderate earthquake. They have an immediate occupancy performance level during a large earthquake (MCE) to reduce the risk of fatalities after a building collapse when an earthquake occurs.

Performance-based seismic design (PBSD) makes it easier for the engineer to determine the selected level of structural performance. PBSD is a structural design where the design criteria are expressed in terms of the expected performance when the structure is subjected to earthquake loads. With this PSBD method, realistically, the risk of life and economic losses can be predicted if an earthquake occurs. PBSD is an iterative process in which the designer begins by setting performance objectives, followed by an initial design, analyzing the initial design whether it is following the performance targets, and finally, redesign and reassessment are carried out if necessary until the desired performance level is achieved [2][3]. The flow of this method starts from choosing the desired performance level, designing according to the performance level, and after the design is completed, the design target can become acceptance criteria through performance evaluation for the performance target level set by FEMA 356. However, the PBSD method depends primarily on an iteration process from evaluating performance to modifying design until the design structure achieves the desired performance

In recent years, we have developed a performancebased plastic design (PBPD) methodology to consider the inelastic characteristic of the structural component [4].

\subsection{PBPD method}

The Performance-Based Plastic Design (PBPD) method is a method with a design concept that considers the inelastic behavior of the structure with little or no iteration during the initial design. This method applies the concept of energy balance by determining the design yield mechanism in advance, as shown in Fig. 1.

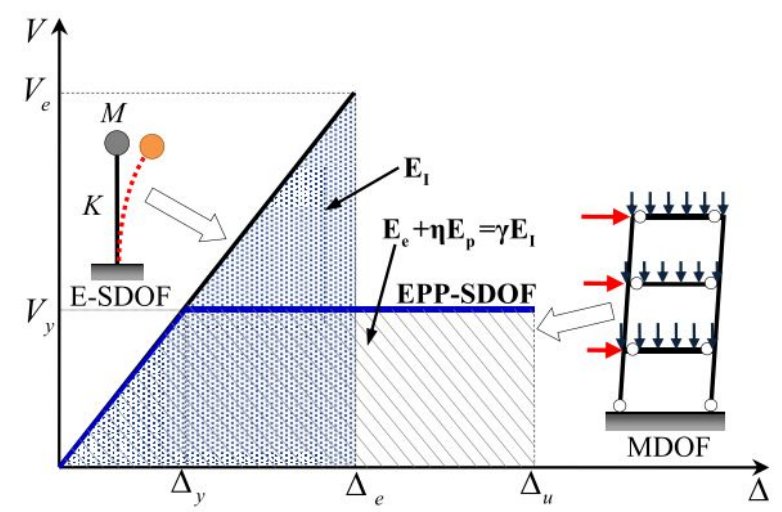

Fig. 1. Illustration of energy balance concept in PBPD [5]

\footnotetext{
* Corresponding author: jati@eng.unand.ac.id
} 
The structural performance as planned is obtained when receiving a strong earthquake [6]. In reinforced concrete structures, it is widespread that there will be a reduction in the stiffness and strength of the structure. This reduction in strength and stiffness is also known as pinching. With the reduction in strength and stiffness in this reinforced concrete structure, a coefficient of $\mathrm{C}_{2}$ is needed. The coefficient $\mathrm{C}_{2}$ is a modifying factor to show the hysterical closed circuit, reduced stiffness, and reduced strength which are the main characteristics of hysteresis behavior. $\mathrm{C}_{2}$ was chosen to modify the target drift plan [7].

\subsection{Comparison of PBPD and Current Code Design Method}

Indonesia already has code SNI 1726:2019 [1] regarding procedures for planning earthquake resistance for building and non-building structures to calculate earthquake loads. In this code, the design base shear is calculated by reducing the elastic strength demands to the inelastic strength demands by incorporating a seismic force-reduction factor $\mathrm{R}$. This reflects the degree of inelastic response expected for design-level-ground motions as the ductility capacity of the structure.

In this code, it is also arranged how to design the structure by paying attention to the desired structure performance. For the design of earthquake-resistant structures, usually, the performance-based seismic design is used by applying a non-elastic pushover load where the lateral force is obtained from the equivalent static-load procedure [8][9]. This lateral force is also the equivalent of the shear force obtained by applying the response spectra map in Indonesia.

As mentioned before, the key of the PBPD method is the preselected target drift and yield mechanism. The lateral design forces are determined for the given seismic load and selected target drift. Therefore, $R, I$, and $C_{d}$ are not needed.

\section{Design Procedure of PBPD}

The PBPD method is used to determine the first yield target of structural elements by determining the displacement target first. After that, the complete structural element design is carried out and analyzed until it reaches the ultimate limit of the entire structure [10].

A key element in the PBPD method is given hazard level to determine the design base shear [5][10][11]. It is calculated by equating the work needed to push the structure monotonically up to the target drift [10]. The work requires an equivalent elastic-plastic single degree of freedom system to achieve the same state. Assuming an idealized elastic-plastic single degree of freedom as shown in Fig. 1, the work-energy equation can be written as

$$
\left(E_{e}+E_{p}\right)=\gamma \cdot\left(\frac{1}{2} M \cdot S_{v}{ }^{2}\right)=\frac{1}{2} \gamma \cdot M \cdot\left(\frac{T}{2 \pi} S_{a} \cdot g\right)^{2}
$$

Where $E_{\mathrm{e}}$ and $\mathrm{E}_{\mathrm{p}}$ are the elastic and plastic components of the energy (work) needed to push the structure up to the target drift. $\mathrm{S}_{\mathrm{v}}$ is the design pseudo-spectral velocity; $\mathrm{S}_{\mathrm{a}}$ is the pseudo-spectral acceleration; $\mathrm{T}$ is the natural period, and $\mathrm{M}$ is the system's total mass.

Outline procedures of PBPD [8] are presented as

a. Selected the desired yield mechanism and target drift as design earthquake load.

b. Estimate the yielding $\operatorname{drift}\left(\theta_{\mathrm{y}}\right)$, the fundamental period $(\mathrm{T})$ of the structure. Then determine an appropriate vertical distribution of lateral design forces of the structure.

c. Determine the elastic design spectral acceleration value, $\mathrm{Sa}$

d. Calculate the design base shear (V)

e. Modify V as needed from the assumed elastic and PDelta effect.

f. Use plastic method to design the designed yielding member.

\section{Methodology}

In this study, the lateral load calculation is calculated based on SNI 1726:2019 and PBPD. This lateral load will be applied to the structure at the center of mass as a nonlinear static lateral load or the pushover analysis method. In this study, what will be compared is the actual ductility value and the level of structural performance from the two lateral load calculations.

The function of the reinforced concrete structure in this study is an educational building with 10 stories, a building length of $42 \mathrm{~m}$, a building width of $48 \mathrm{~m}$, and a building height of $40 \mathrm{~m}$. Concrete has $\mathrm{fc}^{\prime} 30 \mathrm{MPa}$ for columns, beams, and slabs, and fc' $35 \mathrm{MPa}$ for shear walls. The dimension of the main beam is $50 \mathrm{~cm} \mathrm{x} 80 \mathrm{~cm}$ and 30 $\mathrm{cm} \times 50 \mathrm{~cm}$ for joist. There are three types of columns: $100 \mathrm{~cm} \times 100 \mathrm{~cm}$ for the column on the first to the fourth story, $90 \mathrm{~cm} \times 90 \mathrm{~cm}$ for the fifth to the seventh story, and $80 \mathrm{~cm} \times 80 \mathrm{~cm}$ for the eighth to the tenth story.

Building modeling can be seen in Figs. 1 (a) and (b).

\subsection{Lateral Load Using SNI 1726:2019}

Based on Table 3 of SNI 1726:2019, the Education building is included in risk category IV, and according to Table 4 of SNI 1726:2019, the value of the earthquake priority factor (Ie) is 1.5. Based on the earthquake map for Padang city, the value of $S_{s}$ is 1.499 , and $S_{1}$ is 0.6 . Based on Table 3 of SNI 1726:2019, the Education building is included in risk category IV, and according to Table 4 of SNI 1726:2019, the value of the earthquake priority factor (Ie) is 1.5. Furthermore, based on the provisions in the code (SNI 1726:2019), based on the earthquake map for Padang, the value of $\mathrm{S}_{\mathrm{s}}$ is 1.499 , and $\mathrm{S} 1$ is 0.6 . So that the value of $\mathrm{S}_{\mathrm{DS}}=2 / 3\left(\mathrm{~S}_{\mathrm{MS}}\right)=2 / 3 \times 1.499 \mathrm{~g}=0.999$ and the value of $\mathrm{S}_{\mathrm{D} 1}=2 / 3\left(\mathrm{~S}_{\mathrm{M} 1}\right)=2 / 3 \times 1.02 \mathrm{~g}=0.68$.

Based on Tables 8 and 9 for Education buildings with $\mathrm{S}_{\mathrm{DS}}$ values $=0.999$ and $\mathrm{S}_{\mathrm{D} 1}=0.68$, they are included in the seismic design category D. Based on Table 18 for moment-bearing frame structures, $C_{t}=0.0466$ and $x=0.9$ values are obtained. Based on Table 12 for the special moment-bearing reinforced concrete frame structure, the value of $\mathrm{R}=8$. The calculation of the Seismic Response 
Coefficient (Cs) is 0.085 . Then the base-shear force of the design earthquake is $\mathrm{Cs} \times \mathrm{W}$ total $=0.085 \times 165354 \mathrm{kN}$.

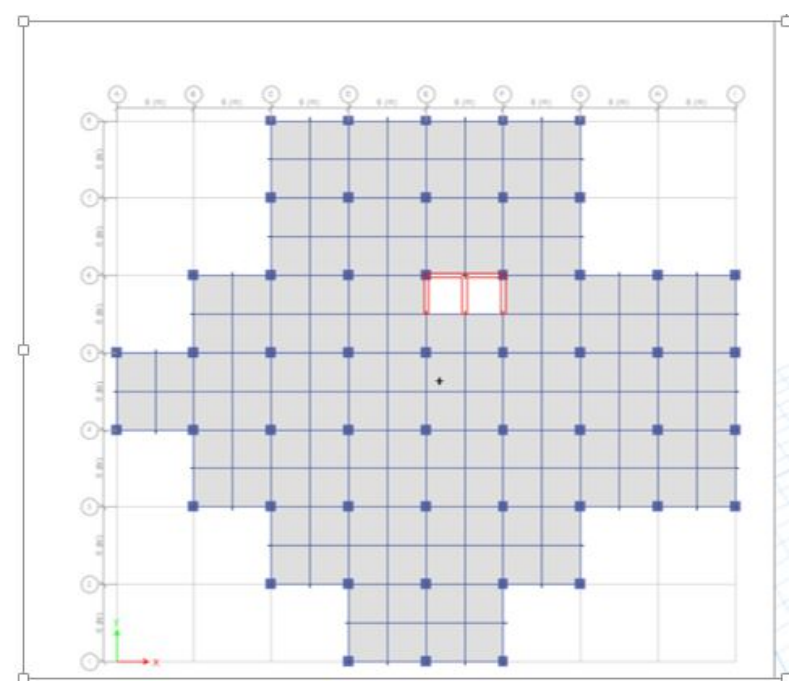

(a)

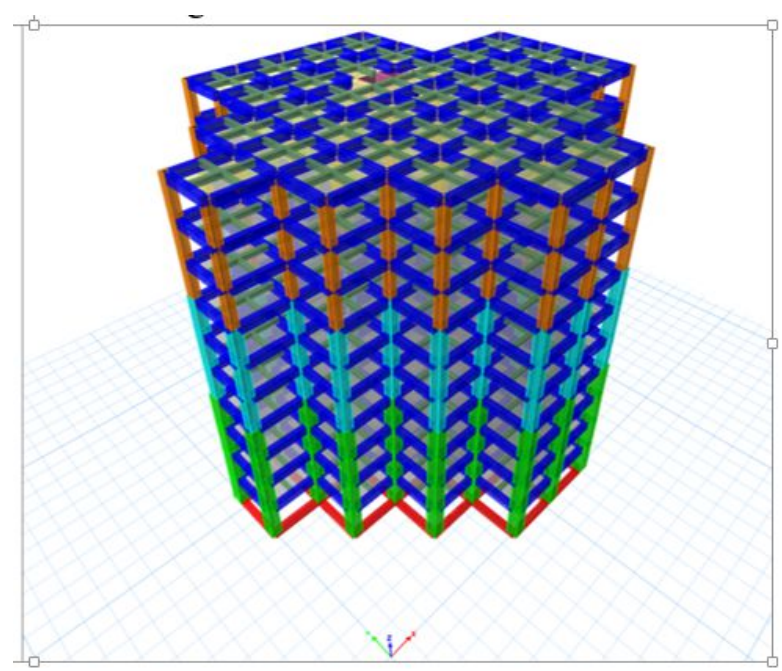

(b)

Fig. 2. Structural modeling (a) structure plan (b) 3D Model of the structure

Table 1. Lateral load for each story using SNI 1726:2019

\begin{tabular}{|c|c|c|c|}
\hline Story & $\mathbf{W}_{\mathbf{x}}(\mathbf{k N})$ & $\mathbf{h}_{\mathbf{x}} \mathbf{( m )}$ & $\mathbf{F}_{\mathbf{i}}(\mathbf{k N})$ \\
\hline 10 & 12871,52 & 40 & 2480 \\
\hline 9 & 16079,53 & 36 & 2671 \\
\hline 8 & 16079,53 & 32 & 2263 \\
\hline 7 & 16201,96 & 28 & 1889 \\
\hline 6 & 17042,01 & 24 & 1600 \\
\hline 5 & 16830,12 & 20 & 1222 \\
\hline 4 & 17001,52 & 16 & 902 \\
\hline 3 & 17890,54 & 12 & 633 \\
\hline 2 & 17678,64 & 8 & 354 \\
\hline 1 & 17678,64 & 4 & 133 \\
\hline
\end{tabular}

\subsection{Lateral Load Using PBPD}

The fundamental period, $\mathrm{T}$ for the reinforced concrete frame, can be determined from the following equation, as given in ASCE 7 - 05 (2006):

$$
\mathrm{T}=\mathrm{C}_{\mathrm{u}} \cdot \mathrm{T}_{\mathrm{a}}=\mathrm{C}_{\mathrm{u}} \cdot \mathrm{C}_{\mathrm{t}} \cdot \mathrm{h}^{\mathrm{n}} \mathrm{X} \text { if } \mathrm{T}_{\text {actual } / \text { model }}>\mathrm{C}_{\mathrm{u}} \cdot \mathrm{C}_{\mathrm{t}} \cdot \mathrm{h}_{\mathrm{n}}{ }^{\mathrm{x}}
$$

where $T_{a}$ is the approximate fundamental period, $C_{u}$ represents the coefficient for the upper limit on the calculated period. The value of $\mathrm{T}$ obtained is 1.805 .

The value of the coefficient $\mathrm{C}_{2}$ is calculated using equation (3)

$$
\mathrm{C}_{2}=1.1-0.045(\mathrm{~T}-0.8)
$$

The coefficient value of $\mathrm{C}_{2}$ is obtained at 1.055 .

Plastic Rotation $\left(\theta_{\mathrm{p}}\right)$ is calculated using equation (4)

$$
\theta_{\mathrm{p}}=\theta_{\mathrm{u}} / \mathrm{C}_{2}-\theta_{\mathrm{y}}
$$

The value of the drift target $\left(\theta_{\mathrm{u}}\right)$ is planned at $2 \%$ for the structure's condition still in operational performance. The yield drift ratio $\left(\theta_{\mathrm{y}}\right)$ can be seen in Table 3-1 (Liao, 2010). From that table, the reinforced concrete structure has a yield drift ratio of $0.5 \%$. With the value of the $\mathrm{C}_{2}$ coefficient of 1.055 , the value of $\theta_{p}$ is $1.396 \%$.

Ductility $\left(\mu_{\mathrm{s}}\right)$ is calculated using equation (5)

$$
\mu_{s}=\frac{\theta_{u}}{\theta_{y \cdot c_{2}}}
$$

Then the ductility value is 3.792 .

Variable Factors for the Energy Balance Equation $(\gamma)$ is calculated using equation (6)

$$
\gamma=\frac{2 \mu_{\mathrm{s}}-1}{\mathrm{R} \mu^{2}}
$$

$R_{\mu}$ value obtained from Table 3-2 (Liao, 2010). $R_{\mu}=\mu_{s}$, which is equal to 3.792. Thus, the value of the variable factor for the Energy Balance Equation $(\gamma)$ is 0.458 .

Shear Force Comparison Factor $\left(\beta_{\mathrm{i}}\right)$ is calculated using equation (7)

$$
\beta_{i}=\left(\frac{\sum_{i=1}^{n} w_{i} \times h_{i}}{w_{n} \times h_{n}}\right)^{0,75 . T^{-0,2}}
$$

where $w_{n} x h_{n}$ is the product of the weight of the structure and the height of the structure on the top floor, then the value of I for each floor is obtained in Table 2.

Design Shear Force Parameter $(\alpha)$ is calculated using equation (8)

$\alpha=\left(\sum_{i=1}^{n}\left(\beta_{i}-\beta_{i+1}\right) h_{i}\right)\left(\frac{w_{n} \times h_{n}}{\sum_{i=1}^{n} w_{i} \times h_{i}}\right)^{0,75 . T^{-0,2}}\left(\frac{\theta_{p} 8 \pi^{2}}{T^{2} g}\right)$

then the value of the Design Shear Force Parameter $(\alpha)$ is 1.042 .

Design Earthquake Base Shear Force (V) is calculated using equation (8)

$$
\frac{v}{w}=\frac{-\alpha \pm \sqrt{\alpha^{2}+4 \gamma C e^{2}}}{2}
$$


then the value of the Basic Earthquake Shear Force (V) is obtained at $55074.983 \mathrm{KN}$.

Table 2. Shear force comparison factor $(\beta \mathrm{i})$

\begin{tabular}{|c|c|}
\hline Story & $\boldsymbol{\beta}_{\mathbf{i}}$ \\
\hline 10 & 1,000 \\
\hline 9 & 1,652 \\
\hline 8 & 2,136 \\
\hline 7 & 2,521 \\
\hline 6 & 2,844 \\
\hline 5 & 3,097 \\
\hline 4 & 3,294 \\
\hline 3 & 3,445 \\
\hline 2 & 3,543 \\
\hline 1 & 3,592 \\
\hline
\end{tabular}

Top-Stage Lateral Force $\left(F_{n}\right)$ is calculated using equation

$$
F_{n}=v\left(\frac{w_{n} \times h_{n}}{\sum_{i=1}^{n} w_{i} \times h_{i}}\right)^{0,75 . T^{-0,2}}
$$

then the lateral force value on the top level of the structure $\left(\mathrm{F}_{\mathrm{n}}\right)$ is $15334 \mathrm{kN}$. Lateral force at the level $\mathrm{I}\left(\mathrm{F}_{\mathrm{i}}\right)$ is calculated using equation (10)

$$
\mathrm{F}_{\mathrm{i}}=\left(\boldsymbol{\beta}_{\mathrm{i}}-\boldsymbol{\beta}_{\mathrm{i}+1}\right) \mathrm{F}_{\mathrm{n}}
$$

when $i=n$, then $\beta_{i+1}=0$, The value of the lateral force is obtained as follows

Table 3. Lateral load per-floor using PBPD

\begin{tabular}{|c|c|}
\hline Story & Fi (kN) \\
\hline 10 & 15334 \\
\hline 9 & 10002 \\
\hline 8 & 7424 \\
\hline 7 & 5900 \\
\hline 6 & 4955 \\
\hline 5 & 3875 \\
\hline 4 & 3019 \\
\hline 3 & 2320 \\
\hline 2 & 1501 \\
\hline 1 & 743 \\
\hline
\end{tabular}

\section{Results and discussion}

4.1 Base Shear and Lateral Force

From Table 4, it can be seen that the magnitude of the base shear force from the PBPD method is more significant than using SNI 1726:2019. The lateral force calculated using SNI 1726:2019 has increased from floors 1-9 and decreased on the 10th floor, while for the PBPD method, the value of lateral forces has increased from floors 1-10. The comparison of the values of these lateral forces is shown in Table 5.

Table 4. Base shear

\begin{tabular}{|c|c|c|}
\hline & SNI 1726:2019 $(\mathrm{kN})$ & PBPD $(\mathrm{kN})$ \\
\hline $\mathrm{V}$ & 14146 & 55075 \\
\hline
\end{tabular}

Table 5. Lateral load

\begin{tabular}{|c|c|c|}
\hline Story & SNI 1726:2019 $(\mathrm{kN})$ & PBPD $(\mathrm{kN})$ \\
\hline 10 & 2480 & 15334 \\
\hline 9 & 2671 & 10002 \\
\hline 8 & 2263 & 7424 \\
\hline 7 & 1889 & 5900 \\
\hline 6 & 1600 & 4955 \\
\hline 5 & 1222 & 3875 \\
\hline 4 & 902 & 3019 \\
\hline 3 & 633 & 2320 \\
\hline 2 & 354 & 1501 \\
\hline 1 & 133 & 743 \\
\hline
\end{tabular}

\subsection{Structural Ductility Analysis}

The ductility of the structure is done by doing a pushover analysis of the structure. The amount of ductility can be determined directly by the ETABS v16 software. The ductility value for lateral forces based on SNI 1726:2019 is obtained at 3.052, while based on PBPD, the value is 3.115. Based on the value of the structure's ductility, the structure with the lateral load using the PBPD method has an actual ductility that is greater than the ductility of the lateral load of the SNI 1726:2019 method.

\subsection{Structure Performance Level}

The performance level of the structure is determined based on the capacity spectrum, where the process begins by analyzing the load versus displacement relationship curve by taking into account the inelastic conditions of the structure. After the performance point is obtained, then the level of structure performance is determined by referring to the provisions of ATC-40 as shown in Table 6.

Table 6. Performance level based on ATC-40

\begin{tabular}{|l|c|c|c|c|}
\hline \multirow{2}{*}{$\begin{array}{l}\text { Parame } \\
\text { ter }\end{array}$} & \multicolumn{4}{|c|}{ Performance level } \\
\cline { 2 - 5 } & $\begin{array}{c}\text { Immediate } \\
\text { Occupancy }\end{array}$ & $\begin{array}{c}\text { Damag } \\
\text { e } \\
\text { control }\end{array}$ & $\begin{array}{c}\text { Life } \\
\text { Safet } \\
\text { y }\end{array}$ & $\begin{array}{c}\text { Structura } \\
\text { I stability }\end{array}$ \\
\hline $\begin{array}{l}\text { Maximu } \\
\text { m total } \\
\text { drift }\end{array}$ & 0.01 & $\begin{array}{c}0.01- \\
0.02\end{array}$ & 0.02 & $0.33 \mathrm{Vi} / \mathrm{Pi}$ \\
\hline $\begin{array}{l}\text { Maximu } \\
\text { m } \\
\text { inelastic } \\
\text { total } \\
\text { drfit }\end{array}$ & 0.005 & $0.005-$ & $\begin{array}{c}\text { No } \\
\text { limit }\end{array}$ & No limit \\
\hline
\end{tabular}

From Fig. 3, the performance point for structures with lateral load based on SNI 1726:2019 is marked by the intersection between the capacity (the green line) and the single demand (red line) so that the results of this pushover analysis can determine the level of structure performance

Maximum total drift is $\mathrm{D}_{\max } / \mathrm{h}=(754.242 / 40000)=$ 0.019 . The value of maximum inelastic total drift is (D$\left.\mathrm{D}_{\text {yield }}\right) / \mathrm{h}=(754.242-186.415) / 40000=0.014$. Based on ATC-40, this condition is included in the level of damage control. In the event of an earthquake, the building is still able to withstand the earthquake, and the risk of loss of life is minimal. 


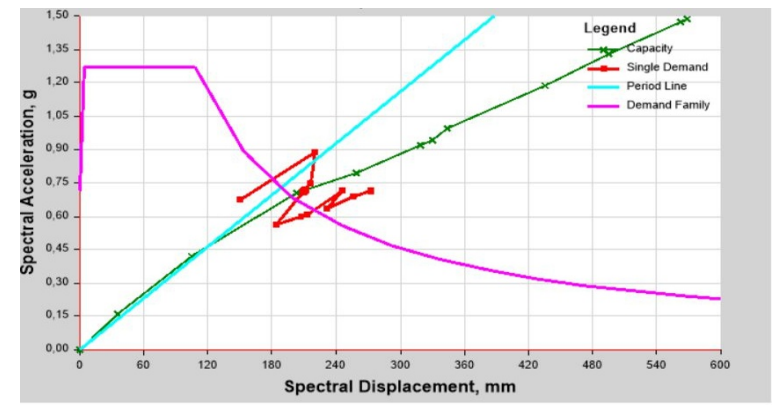

Fig. 3. Performance point structure using SNI 1726: 2019.

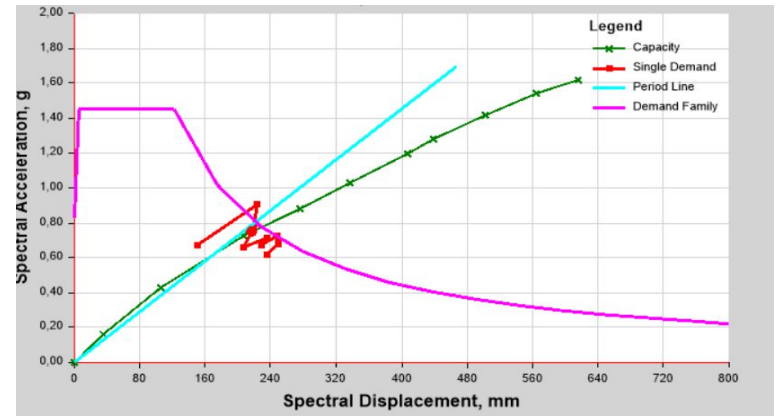

Fig. 4. Performance point structure using PBPD

Based on Fig. 4, the performance point for structures with lateral load based on the PBPD method is obtained from the intersection between capacity (green line) and single demand (red line. In the initial planning, a drifting target $(\theta \mathrm{u})$ was set at 0.02 .

Maximum total drift is $\mathrm{D}_{\max } / \mathrm{h}=(799.928 / 40000)=$ 0.02 (as same as initial drift target). The value of maximum inelastic total drift is $\left(\mathrm{D}-\mathrm{D}_{\text {yield }}\right) / \mathrm{h}=(799.928-$ $197.742) / 40000=0.015$. Based on ATC-40, this condition is included in the level of life safety. In the event of an earthquake, the building is still stable, and the building can still be used if repairs are made.

\section{Conclusion}

Preselected target drift and yield mechanism is a key performance objective in the PBPD method. The PBPD frame model responded as intended in this research to improve their performances over the corresponding baseline frames. In addition, the basic work-energy equation can be used for seismic evaluation purposes to determine expected displacement demand for a given structure and earthquake risk.

Some conclusions that can be drawn from this research are:

a. The base shear force and lateral load on the structure will be greater if it is calculated using the PBPD method than SNI 1726: 2019.

b. By using SNI 1726:2019, the structure has a level of damage control performance. In this situation, the building is still able to withstand earthquakes when earthquakes occur, and the risk of loss of life is minimal c. At the same time, the performance level of the structure with lateral forces calculated using the PBPD method is life safety. In an earthquake, the building is still stable, and the building can still be used if repairs are made.

Acknowledgments to Civil Engineering Department, Engineering Faculty, Andalas University which has funded this research with the contract number: 125/UN16.09.D/PL./2021

\section{References}

1. National Standardization Agency, "Sni 1726-2019," Planning Ordinance. Earthquake Resilience For Structure. Buildings and Non-Buildings, 8 (2019)

2. F. Naeim, "Performance-based seismic design of tall buildings-A USA perspective," in Seismic Isolation, Structural Health Monitoring, and PerformanceBased Seismic Design in Earthquake Engineering: Recent Developments (2018)

3. F. Naeim, "Performance-Based Seismic Design of Tall Buildings," Geotech. Geol. Earthq. Eng.,17, (2010)

4. S. C. Goel, W. C. Liao, M. R. Bayat, and S. H. Chao, "Performance-based plastic design (PBPD) method for earthquake-resistant structures: An overview," Structural Design of Tall and Special Buildings,19, 1-2, (2010)

5. J. Bai, T. Y. Yang, and J. Ou, "Improved Performance-Based Plastic Design for RC Moment Resisting Frames: Development and a Comparative Case Study," Int. J. Struct. Stab. Dyn.,18, 4, (2018)

6. N. J. S. Eem Ikhsan, “ Behavior of steel structure type mrf with lateral load based on sni 1726-2012 and performance based plastic design (pbpd) method " $J$. Tek. Sipil, 13, 1 (2014)

7. Q. Zhang, E. Xiong, X. Liang, and X. Miao, "Performance-based plastic design method of highrise steel frames," J. Vibroengineering, 19 (3), (2017)

8. C. P. D. Amoussou, H. Lei, Y. Halabi, and W. Alhaddad, "Performance-based seismic design methodology for tall buildings with outrigger and ladder systems," Structures, 34 (2021)

9. B. Rangel, A. S. Guimarães, A. Vaz Sá, and F. B. Alves, "Integrated design concept in civil engineering education," Int. J. Eng. Educ., 32, 3, (2016)

10. W. C. Liao and S. C. Goel, "Performance-based plastic design and energy-based evaluation of seismic resistant RC moment frame," J. Mar. Sci. Technol.,20, 3 (2012)

11. S. Leelataviwat, P. Doung, and N. Naiyana, "A Review on Performance-Based Plastic Design Method: Concept and Recent Developments," in Lecture Notes in Civil Engineering, 155 LNCE, (2021) 